\title{
FAMILIAL DIFFERENCES IN THE PROPORTION OF ABNORMAL HEMOGLOBIN PRESENT IN THE SICKLE CELL TRAIT ${ }^{1}$
}

\author{
BY JAMES V. NEEL, IBERT C. WELLS 2 AND HARVEY A. ITANO ${ }^{3}$ \\ (From the Heredity Clinic, University of Michigan, Ann Arbor, Michigan, and the Gates and \\ Crellin Laboratories of Chemistry, ${ }^{4}$ California Institute of Technology, Pasadena, \\ California)
}

(Submitted for publication June 7, 1951; accepted August 6, 1951)

It has recently been shown that the sickling phenomenon exhibited by the erythrocytes of approximately 10 per cent of American Negroes is associated with, and presumably due to, the presence of an abnormal type of hemoglobin molecule (1). In 42 individuals who had only the sickle cell trait, the proportion of abnormal hemoglobin present, as studied by the techniques of electrophoresis, was found to vary from 24 to 45 per cent. In individuals with sickle cell anemia, on the other hand, the proportion of abnormal hemoglobin was usually 100 per cent, although occasionally a small amount of normal hemoglobin was present $(1,2)$. The sickling phenomenon has been known for many years to have a genetic basis ( 3 ), although the exact relationship between the sickle cell trait and full blown sickle cell disease has remained obscure. Recent studies have suggested that the sickling trait and sickle cell disease are related as heterozygote to homozygote, i.e., that there is a gene which when present in single dose results in the sickle cell trait, and when present in double dose, in sickle cell anemia $(4,5)$. In other word's, there exists, primarily in Negro populations, a gene which when represented once in an individual's genetic complex is capable of directing the synthesis of 24 to 45 per cent of the total hemoglobin value along abnormal paths, and when represented twice, results in 85 to 100 per cent of the hemoglobin being of this abnormal type. It has further been shown that although this genetic explanation is

1 This investigation has been aided by grants from the U. S. Public Health Service.

2 Postdoctoral Fellow of the Division of Medical Sciences of the National Research Council. Present address, College of Medicine, State University of New York, Syracuse, New York.

${ }^{3}$ Assigned to the California Institute of Technology by the National Cancer Institute of the National Institutes of Health, Public Health Service, Federal Security Agency.

4 Contribution No. 1581. adequate to account for the great majority of cases of sickle cell disease, a condition which very closely resembles sickle cell disease, and which may in some instances be clinically indistinguishable from it, may be produced either by the interaction of a single sickle cell gene with the gene responsible for thalassemia, or by the interaction of a sickle cell gene with a newly described gene also responsible for certain electrophoretic abnormalities in hemoglobin behavior (6-8).

The factors responsible for the variation in the proportion of abnormal hemoglobin present in individuals with the sickle cell trait have been unknown. In five sicklemic persons restudied after intervals of two to four months the proportion of abnormal hemoglobin agreed within the limits of experimental error with the original observation, and it is presumed that the proportion of abnormal hemoglobin remains relatively constant in each individual with the sickle cell trait (2). The present studies have been undertaken in an effort to determine to what extent the observed variations in the amount of abnormal hemoglobin present are related to familial factors. More specifically, in a series of families in which the sickle cell trait is present, will there be significant differences from one family to the next in the proportion of the hemoglobin which is abnormal? The existence of such differences could provide one basis for the clinically observed variations in the severity of sickle cell disease from one family to another.

\section{TECHNIQUES}

The present investigation is concerned with seven families in which the sickle cell trait was present. Each of these families was selected for study because of its large size and the availability of both parents. In order to establish the diagnosis of sickle cell trait as vs. sickle cell anemia, the individuals included in the study were subjected to the following determinations: presence or absence of sickling, erythrocytes per cmm., grams per cent of hemoglobin, hematocrit, leucocytes per cmm., differ- 
ential leucocyte count, and, where indicated, serum bilirubin determinations and reticulocyte counts. The methods of testing for sickling have been described previously (5). On individuals found to sickle, the proportion of abnormal hemoglobin present was determined according to the methods described by Pauling and associates (1) and Wells and Itano (2). For each family it is known that only one parent exhibited the sickle cell trait, the other parent being normal in this respect. This was an essential prerequisite to a study of this nature, since in the event the value observed in a child departed from that found in one parent, it was necessary to know that it was not from the other parent that the child had inherited the gene for sickling. Serological studies involving the $\mathrm{A}-\mathrm{B}-\mathrm{O}, \mathrm{M}-\mathrm{N}$, and $\mathrm{Rh}$ blood types were done routinely, as a partial check on paternity.

\section{RESULTS}

The findings are summarized in Figure 1. On two of the families included in the study ( $\mathrm{Hi}$ and $S t$ ), electrophoretic studies were carried out on the non-sickling as well as the sickling members of the families. This was done for the following reason: In a marriage of a sickler with a non-sickler, a ratio among the children of one sickler: one non-sickler is to be expected if the above outlined genetic hypothesis is correct. In a previous study (5), a slight deficiency of individuals with the sickle cell trait was apparent in the pooled data. One possible explanation of this lay in imperfections of the techniques for eliciting sickling, i.e., the failure of present techniques to produce sickling in all individuals who were genetically predisposed to sickle. Were this so, then one might expect to find the abnormal hemoglobin component present occasionally in individuals who failed to sickle. In the $H i$ and $S t$ families, there is apparent a deficiency of sickling children. Thus, out of 11 children tested (exclusive of the index cases), only one sickled. However, none of the 10 non-sickling children was found to possess abnormal hemoglobin. The evidence, as far as it goes, thus suggests that the deficiency of individuals with the sickle cell trait is not due to technical failures.

From Figure 1 it is apparent that although in

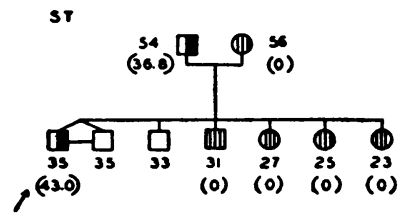

$\omega$
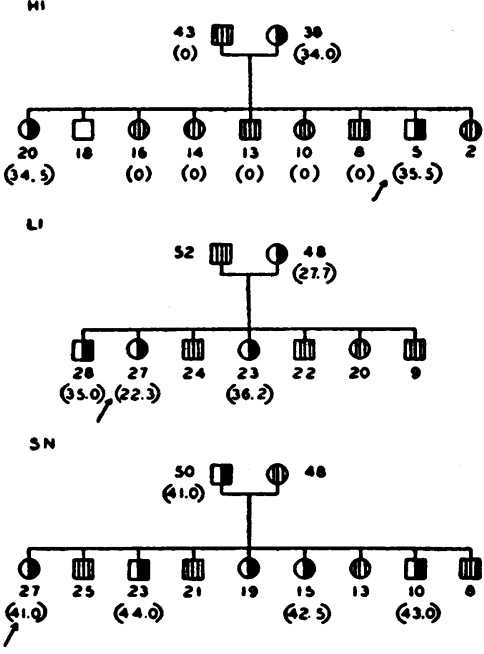

80
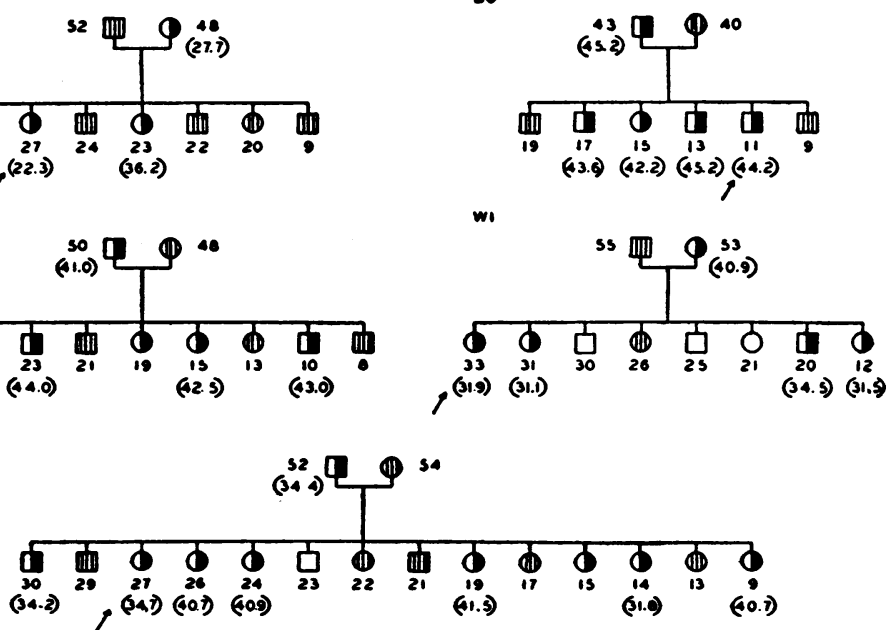

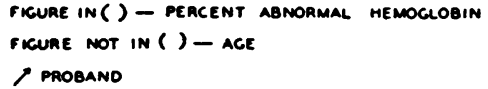

Fig. 1. Pedigrees of the Seven Families Studied, Together with Data on the Percentage of Abnormal Hemoglobin Present in the Sicking Members of These Seven Families 
TABLE I

The relation between sex and the percentage of abnormal hemoglobin present in individuals with the sickle cell trait

\begin{tabular}{|c|c|c|c|}
\hline Kindred & Males & Females & $\begin{array}{c}\text { Difference } \\
\text { (Male average } \\
\text { minus }\end{array}$ \\
\hline $\mathrm{Hi}$ & 35.5 & $\begin{array}{l}34.0 \\
34.5\end{array}$ & \\
\hline Av. & 35.5 & 34.3 & 1.2 \\
\hline $\mathrm{Li}$ & 35.0 & $\begin{array}{l}27.7 \\
22.3 \\
36.2\end{array}$ & \\
\hline Av. & 35.0 & 28.7 & 6.3 \\
\hline Bo & $\begin{array}{l}45.2 \\
43.6 \\
45.2 \\
44.2\end{array}$ & 42.2 & \\
\hline Av. & 44.6 & 42.2 & 2.4 \\
\hline Sn & $\begin{array}{l}41.0 \\
44.0 \\
43.0\end{array}$ & $\begin{array}{l}41.0 \\
42.5\end{array}$ & \\
\hline Av. & 42.7 & 41.8 & 0.9 \\
\hline Wi & 34.5 & $\begin{array}{l}40.9 \\
31.9 \\
31.1 \\
31.5\end{array}$ & \\
\hline Av. & 34.5 & 33.9 & 0.6 \\
\hline Wa & $\begin{array}{l}34.4 \\
34.2\end{array}$ & $\begin{array}{l}34.7 \\
40.7 \\
40.9 \\
41.5 \\
31.8 \\
40.7\end{array}$ & \\
\hline Av. & 34.3 & 38.4 & -4.1 \\
\hline All averages & 37.8 & 36.6 & 1.2 \\
\hline
\end{tabular}

general there are familial similarities in the amount of abnormal hemoglobin present, there may also be rather wide differences among the various members of a family. Some families exhibit a notable constancy $(\mathrm{Hi}, \mathrm{Bo}, \mathrm{Sn})$, whereas others are much more variable $(L i, W i, W a)$. The degree of intra-family similarity may be measured by an analysis of variance. Before proceeding to such an analysis, it is necessary to examine the data for an influence of age and sex on the determinations. No significant influence of age is apparent in the data. The situation with regard to sex is somewhat different. It can be seen from Table I that in five of the six families which contain sickling individuals of both sexes, the male member or members exhibit a higher average proportion of abnormal hemoglobin than do the females. In the 40 unrelated individuals with the sickle cell trait studied earlier by Wells and Itano (2), a similar tendency is apparent, the average amount of abnormal hemoglobin present in 16 males with the trait being 39.0 per cent, whereas in 24 females it was 37.3 per cent. It follows from this that, other things being equal, families in which the affected members were all of the same sex, or predominantly of the same sex, would be expected to exhibit less variability in the proportion of abnormal hemoglobin than would those where there was near equality as regards the sexes. However, the effect of sex appears to be small as compared to the total variability (and may actually disappear with the accumulation of further material), and no attempt will be made to correct for it in these limited data.

The simplest method of testing for the significance of the differences observed from one family to the next involves an analysis of the total variance observed in these determinations into two fractions, namely, that between families, and that within families. Such an analysis is summarized in Table II. It is apparent that there are very significant differences between family means.

Wells and Itano (2) drew attention to a possible bimodality in the values obtained for the proportion of abnormal hemoglobin. A similar bimodality is apparent from these data. In Figure 2 the combined data from the two studies have been plotted. A clear tendency towards two modes is apparent, one at 34-36 per cent, and one at 40 42 per cent. The relative heights of these two peaks are not necessarily representative of those to be derived from an extensive analysis of the sick-

TABLE II

An analysis of the variation observed in the percentage of abnormal hemoglobin in individuals with the sickle cell trait

\begin{tabular}{l|c|c|c}
\hline \multicolumn{1}{c|}{ Source of variation } & $\begin{array}{c}\text { Degrees } \\
\text { of } \\
\text { freedom }\end{array}$ & $\begin{array}{c}\text { Sum } \\
\text { of } \\
\text { squares }\end{array}$ & $\begin{array}{l}\text { Mean } \\
\text { square }\end{array}$ \\
\hline All determinations & 31 & $\frac{972.52}{6}$ & $\frac{635.73}{105.96}$ \\
Between family means & $\frac{1}{25}$ & 336.79 & 13.47 \\
Between members of same family & 25 \\
\hline
\end{tabular}

$$
F=\frac{105.96}{13.47}=7.87 \quad P<1 \%
$$




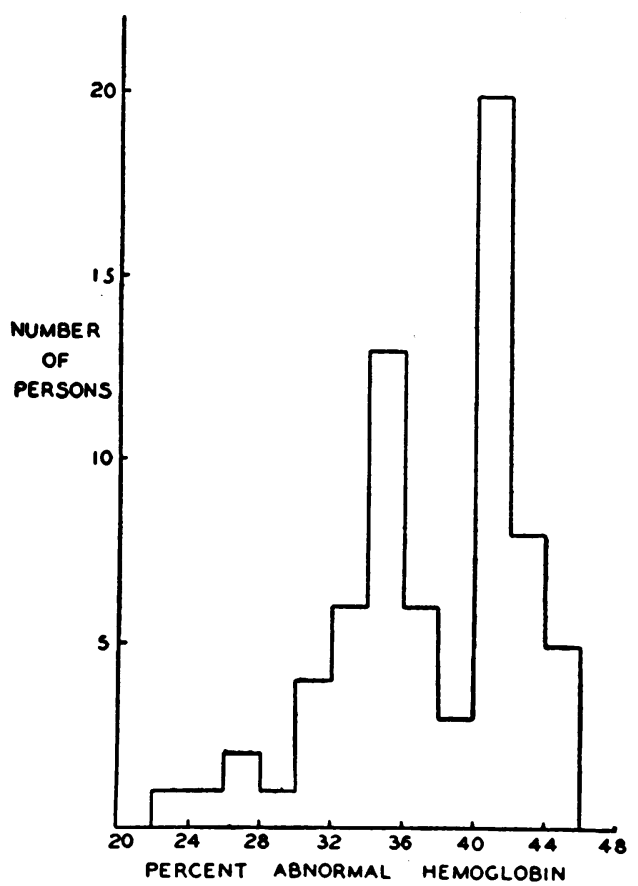

Fig. 2. Frequency Histogram with Respect to the Percentage of Abnormal Hemoglobin Present in the Sickle Cell Trait

Combined data of this study and Wells and Itano (2).

ling population as a whole, inasmuch as the inclusion of family data when the total number of determinations is so low may have biased the findings.

\section{DISCUSSION}

The present data demonstrate clear cut differences among certain families in which the sickling phenomenon is present with respect to the proportion of the hemoglobin which is abnormal in the sickling members of these families. In a number of instances the families studied were widely scattered, and the individuals involved were living under rather diverse circumstances. In the absence of any evidence for significant "environmental" influences on the proportion of abnormal hemoglobin, these differences are presumed to be genetic in origin.

The nature of the genetic mechanism which is assumed to be responsible for these differences is not at present clear. The finding of two modal values with respect to the proportion of abnormal hemoglobin raises the possibility of a genetic dichotomy, such as might be attributed to the existence of two different genes capable of producing the sickling phenomenon, one tending to produce 34 36 per cent abnormal hemoglobin, and the other $40-42$ per cent, with the effects of both genes subject to various modifying influences. However, a scrutiny of the pedigrees in Figure 1 raises doubts as to the validity of this interpretation, which would require that the values observed in the sickling children would agree rather closely with those in the sickling parent. While this is true in some families $(H i, B o, S n)$, in the $W i$ family a parent with 40.9 per cent abnormal hemoglobin has four sickling children in whom the values range between 31.1 and 34.5 per cent, and in the $W a$ family a parent with 34.4 per cent has seven sickling children, three with values between 31.8 and 34.7 per cent, and four with values between 40.7 and 41.5 per cent. This finding suggests that there may be segregating, in American Negro populations, genes capable of influencing significantly the proportion of abnormal hemoglobin present in individuals homozygous or heterozygous for the sickling gene. By way of illustration, it could be postulated that there is a recessive modifying gene $(m)$ capable when homozygous of significantly decreasing the proportion of abnormal hemoglobin produced by a single principal gene responsible for the sickling phenomenon. The results observed in the $W i$ family could be explained thus, where $S k$ represents the gene responsible for the sickling phenomenon, and $s k$ its normal allele:

$$
\begin{aligned}
& \text { Father (high) Mother } \\
& \text { Sksk } M m \times \text { sksk } m \text { mor sksk } M m \\
& \text { Sk sk m m (low) }
\end{aligned}
$$

The four sickling children in the $W i$ family with values significantly lower than their father may be assumed to have received the recessive modifier from both parents. Such a marriage should also produce equal or greater numbers of "high" children like the father; it must be further postulated that by chance none has occurred in this marriage. In the $W a$ family the results may be explained as follows :

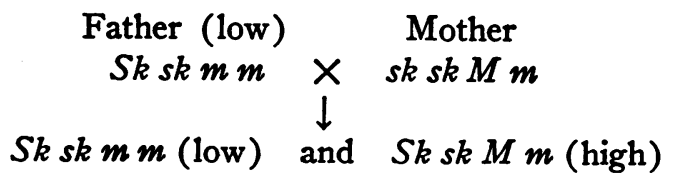

Here the approximately equal numbers of "high" 
and "low" children which one might expect from the theory are present.

Wells and Itano (2) were able to study both parents of two of their anomalous cases of sickle cell anemia with small amounts of normal hemoglobin. In one of these cases, the father had 41.0 per cent abnormal hemoglobin and the mother, 40.5 per cent. In this instance both parents could have been heterozygous for the recessive modifier which has been postulated, the child then being homozygous for the modifier.

It should be emphasized that the above scheme is supplied only to illustrate how genetic modifiers could be responsible for the observed results. It would be premature to postulate that this is in fact the actual situation. At this stage in the analysis it does not appear that we are justified in reaching any more definite conclusions than that:

1. There may exist sickle cell genes which differ in the proportion of abnormal hemoglobin for which they are characteristically responsible.

2. There do exist influences, probably at least in part genetic, which are capable of modifying the proportion of abnormal hemoglobin present in an individual heterozygous for the sickling gene.

\section{SUMMARY}

1. Seven Negro families in which the sickle cell trait is present have been investigated by the techniques of electrophoresis with reference to the question of whether there are significant differences between families as regards the proportion of abnormal hemoglobin associated with the trait. These seven families include a total of 74 individuals, of whom 32 are known to have the sickle cell trait and were studied.

2. The proportion of abnormal hemoglobin ob- served in individuals with the sickle cell trait varied from 22.3 per cent to 45.2 per cent. An analysis of this variation into two portions, that between members of the same family, and that between family means, revealed a highly significant difference between family means.

3. This difference between family means is thought to be genetic rather than environmental in origin. However, the nature of the responsible genetic system is not at present clear.

\section{ACKNOWLEDGMENT}

The authors are most grateful to Dr. W. W. Zuelzer and Dr. E. Kaplan of the Children's Hospital of Michigan, Detroit, Michigan, for their many courtesies in connection with this study.

\section{REFERENCES}

1. Pauling, L., Itano, H. A., Singer, S. J., and Wells, I. C., Sickle cell anemia, a molecular disease. Science, 1949, 110, 543.

2. Wells, I. C., and Itano, H. A., Ratio of sickle cell anemia hemoglobin to normal hemoglobin in sicklemics. J. Biol. Chem., 1951, 188, 65.

3. Emmel, V. E., A study of the erythrocytes in a case of severe anemia with elongated and sickle-shaped red blood cells. Arch. Int. Med., 1917, 20, 586.

4. Neel, J. V., The inheritance of sickle cell anemia. Science, 1949, 110, 64.

5. Neel, J. V., The inheritance of the sickling phenomenon, with particular reference to sickle cell disease. Blood, 1951, 6, 389.

6. Powell, W. N., Rodarte, J. G., and Neel, J. V., The occurrence in a family of Sicilian ancestry of the traits for both sickling and thalassemia. Blood, 1950, 5, 887.

7. Itano, H. A., and Neel, J. V., A new inherited abnormality of human hemoglobin. Proc. Nat. Acad. Sc., 1950, 36, 613.

8. Kaplan, E., Zuelzer, W. W., and Neel, J. V., Studies concerning a new inherited abnormality of hemoglobin. Blood, in press. 